Journal of Engineering and Applied Sciences 14 (19): 7059-7063, 2019

ISSN: 1816-949X

(C) Medwell Journals, 2019

\title{
Model and Simulation of Crude Oil Preheating Furnace
}

\author{
Angelica Orjuela, Juan Useche and Dario Amaya \\ Virtual Applications Group-GAV, Nueva Granada Military University (UMNG), Bogota, Colombia \\ u1801708@unimilitar.edu.co
}

\begin{abstract}
An oven is a element that performs a heat transfer of a product (fuel) to another (load). The heat source is the energy released by the controlled combustion of a fuel the combustion products are in gaseous phase they are therefore, called flue gases. In the furnace, it called a coil step is a fixed flow circuit pipe through which the process fluid passes and is heated. Recognizing the importance of the industry in oil refining pattern recognition furnace which is directly involved in the preparation of the oil extracted for the start of the distillation process is necessary. In this working model, simulation and control of an industrial furnace typically used for heating oil, taking into account balances and thermodynamic relationships occurs. The most important result, estimation of functional variables and transfer function corresponding to the dynamics of the oven, the design of PID controller for temperature and system simulation Lao open and closed loop is performed.
\end{abstract}

$\underline{\text { Key words: Furnace, preheating, crude oil, simulation, model, MATLAB }}$

\section{INTRODUTION}

A furnace is used to increase the temperature of a fluid in the oil refining process this equipment performs calo transfer from the flame radiation to the substance and the energy is distributed between increasing temperature and changing the phase (vaporize), usually, greater energy to vaporize the temperature increase (Mullinger and Jenkins, 2013; Gu et al., 2014). The heat released gas becomes heat absorbed in the radiant section, heat absorbed in the convection zone, more losses (Waheed et al., 2014). To prevent loss of heat through the walls into the atmosphere, the furnace wall is a refractory material. Although, the insulation still has losses ranging between 2 and 3\% (Kansha et al., 2012; Benali et al., 2012).

For proper operation the oven has several elements as shown in the Fig. 1, among these are the burners, responsible for introducing air and fuel, the coils formed by tubes, the radiation zone where combustion takes place, the convection zone which recovers additional energy which controls the damper out of the oven and a duct outlet gases to the atmosphere (De Oliveira Filho et al., 2009; Ochoa-Estopier et al., 2014). In normal operation the performance of a furnace is affected by imbalances heat flux (the amount of heat transferred from the heating area) in steps that affect the runtime of the team as they accelerate the formation of coke (carbon layer formed on the inside) wall also induce high temperatures

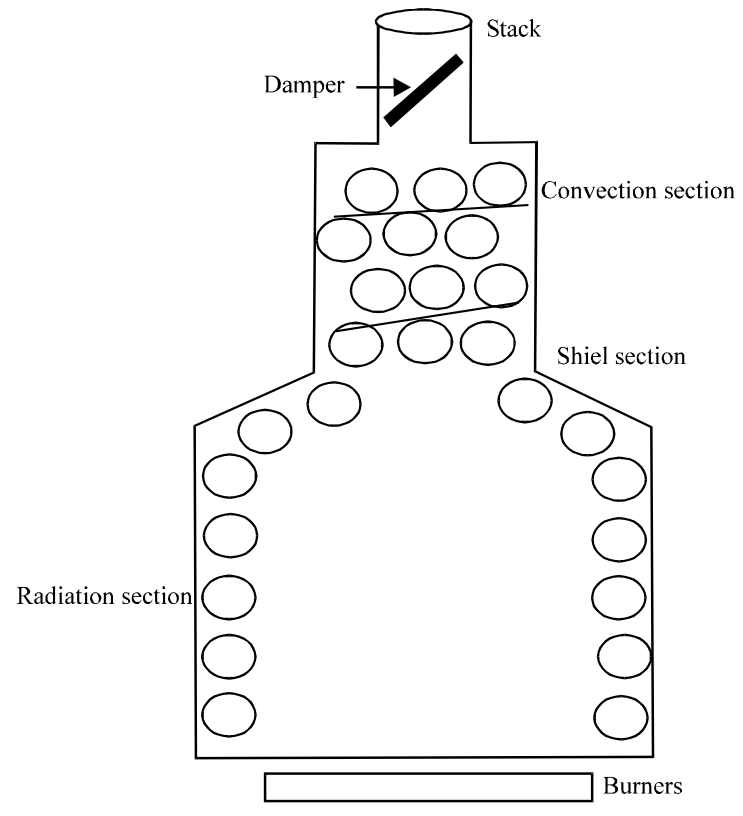

Fig. 1: Crude oil preheating furnace

which reduces the capacity by which closes the tube to prevent rupture (Xing et al., 2013; Luo et al., 2015).

Due to the interaction of variables there is a significant reduction in efficiency that is why the implementation of a system of controls to increase efficiency, maintain stable operation, extending the operating time of the unit increasing the total charge is

Corresponding Author: Angelica Orjuela, Virtual Applications Group-GAV, Nueva Granada Military University (UMNG), Bogota, Colombia, u1801708@unimilitar.edu.co 
required prolong the life of the tubes and improve plant profitability by maximizing heat transfer (Luo et al., 2013; Al Omari and Abu-Jdayil, 2013).

Some of the related work in the area of modeling and simulation is presented by Chaibakhsh et al. (2015) where develop an accurate mathematical model in order to describe the thermal behavior of a crude preheat furnace main outcome have a real time simulation in MATLAB where performance is analyzed at different operating conditions. By Bhourase et al. (2014) developing a modular control system for oil temperature furnace feed is presented by a PLC and the main result PI controller for temperature variable designs which promotes perfect combustion consistency pumping oil.

Regarding the implementation of fuzzy control, this (Chaibakhsh et al., 2012) wherein the mathematical model and the design of a temperature control system for industrial preheating oven develops. The main result of the simulation system is performed with a fuzzy controller maintaining the temperature at $360^{\circ} \mathrm{C}$, proving the robustness of the system in response to various disturbances. Based on the above in this research the model and simulation of a preheating furnace oil used in the oil refining process in order to design a temperature control that meets the same conditions and needs is done of the system.

\section{MATERIALS AND METHODS}

The oven has considered two cases of fire as in Fig. 2, 20 bottom burners mounted which provides the necessary heat to each section. Reaching a temperature of $360^{\circ} \mathrm{C}$ with a flow of $530 \mathrm{ton} / \mathrm{h}$ and an inlet pressure of 16.32 bar. All features are patterned oven in Table 1. The crude oil is first heated by the exhaust gases which heat to increase thermal efficiency and then sent to the main sections of the firebox (Singh and Maji, 2012). Oven for modeling thermodynamic equations and laws apply respective balance, taking into account the flow properties (Chaibakhsh et al., 2012):

$$
\frac{\mathrm{d}}{\mathrm{dt}}\left[\rho \mu . \mathrm{V}+\mathrm{m}_{\mathrm{a}} \cdot \mathrm{C}_{\mathrm{p}} \cdot \mathrm{T}_{\mathrm{a}}\right]=\dot{\mathrm{Q}}+\dot{\mathrm{m}}_{\text {in }} \mathrm{h}_{\text {in }}-\dot{\mathrm{m}}_{\text {out }} \mathrm{h}_{\text {out }}
$$

Equation 1 shows the overall energy balance for the furnace:

$$
\rho . V \frac{\mathrm{dh}}{\mathrm{dt}}+\frac{\mathrm{d}}{\mathrm{dt}}\left[\mathrm{m}_{\mathrm{a}} \cdot \mathrm{C}_{\mathrm{p}} \cdot \mathrm{T}_{\mathrm{a}}\right]=\dot{\mathrm{Q}}+\dot{\mathrm{m}}_{\text {in }} \mathrm{h}_{\text {in }}-\dot{\mathrm{m}}_{\text {out }} \mathrm{h}_{\text {out }}
$$

Equation 2 se obtiene consider and obtained considering that $\mu=$ h-p.V applied to Eq. 1:
Table 1 Reference values for the model of oil preheating furnace

\begin{tabular}{lcc}
\hline Parameter (unit) & Symbols & Values \\
\hline Process fluid flow rate $(\mathrm{kg} / \mathrm{sec})$ & $\dot{\mathrm{m}}_{\text {in }}$ & 73.6 \\
Process fluid inlet temperature $\left({ }^{\circ} \mathrm{C}\right)$ & $\mathrm{T}_{\text {in }}$ & 233 \\
Process fluid outlet temperature $\left({ }^{\circ} \mathrm{C}\right)$ & $\mathrm{T}_{\text {out }}$ & 370 \\
Process fluid inlet pressure $(\mathrm{bar})$ & $\mathrm{P}_{\text {in }}$ & 16.32 \\
Process fluid inlet pressure $(\mathrm{bar})$ & $\mathrm{P}_{\text {out }}$ & 3.22 \\
Combustion air pressure $(\mathrm{bar})$ & $\mathrm{P}_{\text {air }}$ & 1.01 \\
Estimated fuel gas flow rate $(\mathrm{kg} / \mathrm{sec})$ & $\dot{\mathrm{m}}_{\text {fule }}$ & 0.895 \\
Estimated combustion air flow rate $(\mathrm{kg} / \mathrm{sec})$ & $\dot{\mathrm{m}}_{\text {air }}$ & 16.46 \\
Fuel gas lower heating value $(\mathrm{MJ} / \mathrm{kg})$ & $\mathrm{LHV}$ & 47.1 \\
Efficiency of LHV & - & $76 \%$ \\
Metal temperature $\left({ }^{\circ} \mathrm{C}\right)$ & $\mathrm{T}_{\mathrm{a}}$ & 424 \\
Efficient process volume $\left(\mathrm{m}^{3}\right)$ & $\mathrm{V}$ & 4.28 \\
Process fluid density $\left(\mathrm{kg} / \mathrm{m}^{3}\right)$ & $\rho$ & 847 \\
\hline
\end{tabular}

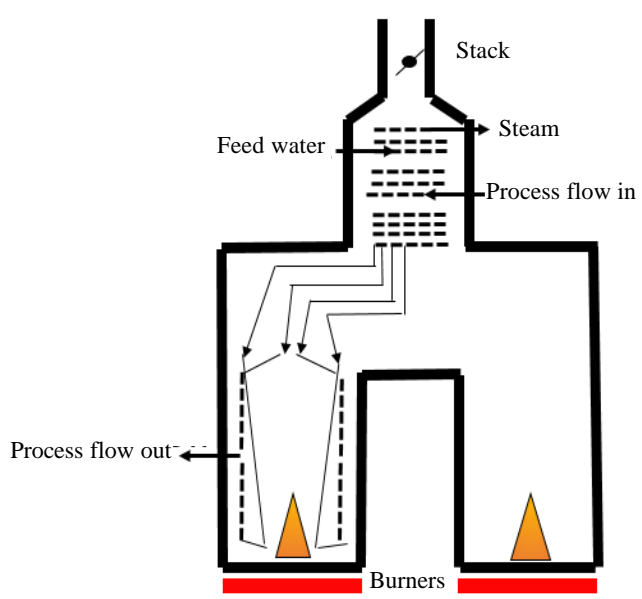

Fig. 2: Preheating furnace diagram crude

$$
\text { p.V.C } \frac{\mathrm{dT}_{\mathrm{put}}}{\mathrm{dt}}+\frac{\mathrm{d}}{\mathrm{dt}}\left[\mathrm{m}_{\mathrm{a}} \cdot \mathrm{C}_{\mathrm{p}} \cdot \mathrm{T}_{\mathrm{a}}\right]=\dot{\mathrm{Q}}+\mathrm{C}_{\mathrm{p}} \dot{\mathrm{m}}_{\text {in }}\left(\mathrm{T}_{\text {in }}-\mathrm{T}_{\text {out }}\right)
$$

Pressure changes occur by varying the furnace load, so, it is considered that $\mathrm{C}_{\mathrm{p}}=\partial \mathrm{h} / \partial \mathrm{Tp}$ and $\mathrm{dh} / \mathrm{dt}=(\partial \mathrm{h} / \partial \mathrm{T})$ (dT/dt), obtaining Eq. 3. In steady state conditions the metal temperature is near the temperature of the process, so, it can be neglected in Eq. 3:

$$
\frac{\mathrm{dT}_{\text {out }}}{\mathrm{dt}}=\frac{1}{\rho \cdot \mathrm{V}}\left[\frac{\dot{\mathrm{Q}}}{\mathrm{C}_{\mathrm{p}}} \dot{\mathrm{m}}_{\text {in }}\left(\mathrm{T}_{\text {in }}-\mathrm{T}_{\text {out }}\right)\right]
$$

Model parameters taken at steady state, applied to Eq. 4 to calculate the heat released by the combustion process:

$$
\begin{gathered}
\mathrm{C}_{\mathrm{a}} \mathrm{H}_{\mathrm{b}}+\gamma\left(\mathrm{a}+\frac{\mathrm{b}}{4}\right)\left(\mathrm{O}_{2}+3.76 \mathrm{~N}_{2}\right) \rightarrow \mathrm{aCO}_{2}+ \\
\frac{\mathrm{b}}{2} \mathrm{H}_{2} \mathrm{O}+\mathrm{dN}_{2}+\mathrm{eO}_{2}+\mathrm{fNO}_{\mathrm{x}}+\mathrm{gCO}+, \ldots
\end{gathered}
$$


The combustion process is modeled based on the chemical reaction. A balanced ratio for any fuel system reaction with air can be represented by Eq. 5 :

$$
\begin{gathered}
\Delta \mathrm{hR}=\mathrm{h}_{\text {prod }}-\mathrm{h}_{\text {react }} \\
\Delta \mathrm{hR}\left(\frac{\mathrm{kJ}}{\mathrm{kg}_{\text {MIX }}}\right)=\left(\frac{\mathrm{m}_{\text {fuel }}}{\mathrm{m}_{\text {fuel }}+\mathrm{m}_{\text {air }}}\right) \Delta \mathrm{hR}=\left(\frac{1}{\frac{\mathrm{A}}{\mathrm{F}}+1}\right) \Delta \mathrm{hR}(7)
\end{gathered}
$$

By defining the enthalpy Eq. 6 as the heat released as a unit by mass, it can be represented by Eq. 7 :

$$
\dot{\mathrm{Q}}=\mathrm{n}_{\mathrm{com}}\left(\dot{\mathrm{m}}_{\mathrm{fuel}} \Delta \mathrm{hR}\left(\frac{\frac{\mathrm{A}}{\mathrm{F}_{\text {com }}+1}}{\frac{\mathrm{A}}{\mathrm{F}_{\text {sto }}+1}}\right)\right)-\mathrm{n}_{\mathrm{prss}}\left(\mathrm{P}_{\text {air }}-\mathrm{P}_{\mathrm{por}}\right)
$$

Changes in the pressure in the furnace may be considered in the combustion model considering proposed by Chaibakhsh et al. (2007). As such AHR Eq. 8 where is the lower calorific value of the fuel is raised, $\mathrm{A} / \mathrm{F}$ is the mass fraction of fuel and air $\mathrm{n}_{\mathrm{corm}}$ and $\mathrm{n}_{\mathrm{prss}}$ are the coefficients of thermal efficiency and furnace pressure, respectively.

Due to load changes or variations in fuel pressure gas furnace heat zones can be changed which has significant effects on the temperature output currents. By increasing the height of the flame, the temperature of the streams at the bottom decreases substantially and flows up overheated. So, it is necessary to consider the variation of the height of the flame in the furnace model:

$$
\mathrm{H}_{\mathrm{f}}=0.235 \dot{\mathrm{Q}}^{2 / 5}-1.02 \mathrm{D}
$$

The height of the burner flame can be estimated using Eq. 9 which was represented by Heskestad (1995) where, $\mathrm{H}_{\mathrm{f}}$ is the flame height $(\mathrm{m}), \mathrm{Q}$ is the flow heat release $(\mathrm{kW})$ and $\mathrm{D}$ is the diameter of the flame. Here, we consider the height of the flame and the nominal size are 3.06 and $1 \mathrm{~m}$, respectively:

$$
\left\{\begin{array}{l}
\mathrm{n}_{\text {ABS }}=1+\lambda\left(\frac{\mathrm{Hf}}{\mathrm{H}_{\text {nominal }}}-1\right)^{\alpha} \text { up side } \\
\mathrm{n}_{\mathrm{ABS}}=1+\lambda\left(\frac{\mathrm{Hf}}{\mathrm{H}_{\text {nominal }}}-1\right)^{\alpha} \text { bottom side }
\end{array}\right.
$$

Also, consider the empirical function on the absorption efficiency with respect to the flame height which corresponds by location as shown in Eq. 10 where $\lambda$ and $\alpha$ parameters have a value of 0.61 and 1.012 , respectively, taken according to, the characteristics of the oven:

$$
\frac{\mathrm{p}}{\rho}+\frac{\mathrm{V}^{2}}{2}=\mathrm{K}=\mathrm{constant}
$$

In order to take into account, the pressure drop in the process, caused by load changes, the Bernoulli equation is used, leaving aside the effects of friction losses and height differences Eq. 11 is obtained:

$$
\dot{\mathrm{m}}_{\max }=\mathrm{C}_{\mathrm{v}} \sqrt{\frac{\left(\mathrm{P}_{\text {in }}-\mathrm{P}_{\text {out }}\right)}{\rho}}
$$

The flow rate of each stream is adjusted by control valves. The mass flow rate $(\mathrm{kg} / \mathrm{sec})$ of liquid through the valve control is related to the pressure drop $(\mathrm{Pa})$ through a fully open valve as shown at 12 . Where, $C_{v}=0.4679$, the coefficient valve. Through this process an approximate linear model is obtained in which the fuel flow to the burners is the input $u(t)$ and the temperature of the crude oil at the furnace exit is the output $y(t)$. The main disturbances are changes in the composition, quality and calorific value of the fuel, incomplete combustion burner, etc. Its effects have been modeled as unmeasured disturbances:

$$
\mathrm{G}_{0}(\mathrm{~s})=\frac{\Delta \mathrm{Y}(\mathrm{s})}{\Delta \mathrm{U}(\mathrm{s})}=\frac{\mathrm{K}_{0}}{\left(1+\mathrm{T}_{10} \mathrm{~s}\right)\left(1+\mathrm{T}_{20} \mathrm{~s}\right)} \mathrm{e}-\mathrm{T}_{0} \mathrm{~s}
$$

As representing the dynamics of the system has the transfer function shown in Eq. 13 generally with values $\mathrm{K}_{0}=3.66^{\circ} \mathrm{C} / \%$ as static gain, $\mathrm{T}_{10}=51.2 \mathrm{~s}$ and $\mathrm{T}_{20}=12.1 \mathrm{~s}$ are the time constants and $\mathrm{T} 0=110 \mathrm{~s}$ :

$$
\mathrm{G}_{0}(\mathrm{~s})=\frac{183}{\left(1+\frac{121}{10} \mathrm{~s}\right)\left(1+\frac{256}{5} \mathrm{~s}\right) * 50} \mathrm{e}^{-110 \mathrm{~s}}
$$

Substituting the values in the transfer function is obtained by Eq. 14. To design the furnace temperature control strategy arises PID:

$$
u(t)=K_{p} e(t)+K_{i} \int_{0}^{t} e(t) d t+K_{d} \frac{d e(t)}{d t}
$$




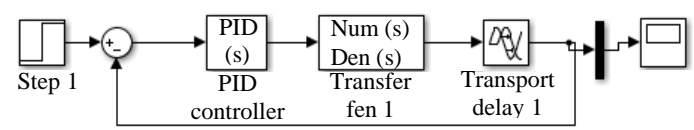

Fig. 3: Block diagram of simulation in MATLAB

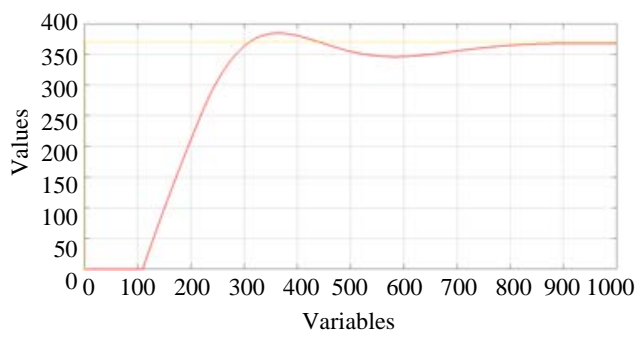

Fig. 4: Graphs of the controlled temperature vs. time

The PID controller requires 3 constants, the proportional, derivative and integral to the design takes into account the Eq. 15. Simulink tool of MATLAB Software is used to tune suitable for the plant control variables and It was simulated as shown in Fig. 3. Figure 4 corresponds to controlled by the manipulated variable is the amount of fuel as shown stabilization time with underdamped behavior corresponds to $800 \mathrm{sec}$ to reach the ideal oil temperature chosen temperature which is $370^{\circ} \mathrm{C}$.

According to the control scheme, if oil becomes heavier and remains constant flow control by the process control and temperature at the outlet of the furnace, gas fuel demand starts to decrease to maintain the temperature of equal to the output end of the test. The heavy oil at the same temperature condition will vaporize less then the energy that supplies the gas will be used mainly for heating.

Once passed the first minutes of the test gas flow decreases then the total mass of gas ascending through the furnace and the amount of heat released decreases is reduced. The mass of gas is mixed with air. If low gas flow temperature then low fire because the heat generated will be absorbed by the radiant zone and convection zone.

\section{CONCLUSION}

Using a traditional controller as PID offers an excellent alternative because it meets the needs of the system and to the majority of disturbances, respond effectively but if you want to consider a wider range of robust range could implement strategies as the MPC. The benefits achieved by implementing the PID controller which allows the plant to operate stably and safely and reduce variability associated with a variable interaction to operate consistently.

The fuel flow measurement is the most direct indication of burning exercise this measure together with the load flow and outlet temperature of the process fluid, constitute the basic measurements to verify the performance of the furnace and shows that the PID controller maintained stability ensured and the maximum utilization of the potential load.

\section{ACKNOWLEDGEMENT}

Special thanks to the Research Vice-rectory of the "Universidad Militar Nueva Granada" for financing the project INV_ING_1911 titled "Laboratorio Virtual para el Control del Proceso de Refinación del Petróleo con Realidad Aumentada y Realidad Virtual" project, 2015 year.

\section{REFERENCES}

Al Omari, S.A.B. and B. Abu-Jdayil, 2013. Some considerations of the performance of small dual fuel furnaces fueled with a gaseous fuel and a liquid fuel mix containing used engine lube oil. Renewable Energy, 56: 117-122.

Benali, T., D. Tondeur and J.N. Jaubert, 2012. An improved crude oil atmospheric distillation process for energy integration: Part I: Energy and exergy analyses of the process when a flash is installed in the preheating train. Appl. Therm. Eng., 32: 125-131.

Bhourase, A., K. Solanki, J. Shah and N. Bhatt, 2014. Preheating of furnace feed oil using PLC. Procedia Technol., 14: 372-379.

Chaibakhsh, A., A. Ghaffari and S.A.A. Moosavian, 2007. A simulated model for a once-through boiler by parameter adjustment based on genetic algorithms. Simul. Modell. Pract. Theor., 15: 1029-1051.

Chaibakhsh, A., M. Pourbeheshtian, M.J. Sigaroudi and H.R. Najafi, 2012. Modeling and fuzzy control of a crude oil preheating furnace. Appl. Mech. Mater., 229: $2370-2374$.

Chaibakhsh, A., N. Ensansefat, A. Jamali, R. Kouhikamali and $\mathrm{H}$. Najafi, 2015. Crude oil direct fired furnace model. Appl. Therm. Eng., 83: 57-70.

De Oliveira Filho, L.O., F.S. Liporace, E.M. Queiroz and A.L.H. Costa, 2009. Investigation of an alternative operating procedure for fouling management in refinery crude preheat trains. Appl. Therm. Eng., 29: 3073-3080. 
Gu, W., Y. Huang, K. Wang, B. Zhang and Q. Chen et al., 2014. Comparative analysis and evaluation of three crude oil vacuum distillation processes for process selection. Energy, 76: 559-571.

Heskestad, G., 1995. Fire plume behavior in temperature-stratified ambients. Combust. Sci. Technol., 106: 207-228.

Kansha, Y., A. Kishimoto and A. Tsutsumi, 2012. Application of the self-heat recuperation technology to crude oil distillation. Appl. Therm. Eng., 43: 153-157.

Luo, S., C. Yi and Y. Zhou, 2013. Bio-oil production by pyrolysis of biomass using hot blast furnace slag. Renewable Energy, 50: 373-377.

Luo, Y., L. Wang, H. Wang and X. Yuan, 2015. Simultaneous optimization of heat-integrated crude oil distillation systems. Chin. J. Chem. Eng., 23: 1518-1522.
Mullinger, P. and B. Jenkins, 2013. Industrial and Process Furnaces Principles, Design and Operation. 2nd Edn., Elsevier Publishing Company, ?Amsterdam, Netherlands, ISBN-13:978-0-08-099377-5, Pages: 639.

Ochoa-Estopier, L.M., M. Jobson and R. Smith, 2014. The use of reduced models for design and optimisation of heat-integrated crude oil distillation systems. Energy, 75: 5-13.

Singh, R. and S. Maji, 2012. Mathematical modeling and simulation of CNG-Diesel dual fuel engine cycle processes. J. Eng. Appl. Sci., 7: 175-183.

Waheed, M.A., A.O. Oni, S.B. Adejuyigbe and B.A. Adewumi, 2014. Thermoeconomic and environmental assessment of a crude oil distillation unit of a Nigerian refinery. Appl. Therm. Eng., 66: 191-205.

Xing, X., D. Dou, Y. Li and C. Wu, 2013. Optimizing control parameters for crude pipeline preheating through numerical simulation. Appl. Therm. Eng., 51: 890-898. 